\title{
Nucleus geometry and mechanical properties of resistance spot welded coated-uncoated DP automotive steels
}

\author{
IBRAHIM SEVIM*, FATIH HAYAT ${ }^{\dagger}$ and MUSTAFA KEMAL KULEKCI ${ }^{\ddagger}$ \\ Department of Mechanical Engineering, Engineering Faculty, Mersin University, 33343 Ciftlikkoy, Mersin, Turkey \\ ${ }^{\dagger}$ Metallurgy Materials Engineering Department, Engineering Faculty, Karabuk University Baliklarkayasi, Karabuk, Turkey \\ †Faculty of Tarsus Technical Education, Mersin University, 33480 Tarsus, Turkey
}

MS received 10 April 2012; revised 5 July 2012

\begin{abstract}
In this study, mechanical properties of resistance spot welding of DP450 and DP600, galvanized and ungalvanized automotive sheets have been investigated. The specimens have been joined by resistance spot welding at different weld currents and times. Welded specimens have been examined for their mechanical, macrostructure and microstructure properties. Depending on the weld current and time, effects of zinc coating on tensile properties, microhardness values as well as microstructure nugget geometry and nucleus size ratio have been investigated. X-ray diffraction analysis has been used to investigate the phase that formed at the joint interface. Result of the experiment show that nugget diameter, indentation depth and tensile load-bearing capacity are affected by weld parameters. Coating prevents full joining at low parameters. Microhardness increased in heat-affected zone and weld metal.
\end{abstract}

Keywords. Automotive steels; resistance spot welding; mechanical properties; nucleus geometry.

\section{Introduction}

Resistance spot welding, which is one of the oldest electric welding processes is a joining technique used for almost all known metals (Sevim 2005; Hayat and Sevim 2012).The weld is made by a combination of heat, pressure and time (Kearns 1980; Aslanlar 2006; Kocabekir et al 2008; Eisazadeh et al 2010). Electrical resistance of the material to be welded causes localized heating at the interface of the metals to be joined. Pressure is exerted by tongs and tips. Time refers to how long the current flows in the joint, which is determined by the material thickness and type, amount of the current and cross-sectional area of the welding tips and contact surfaces (Aslanlar 2006). The process is used in preference to mechanical fasteners, such as rivets or screws, when disassembly for maintenance is not required (Kearns 1980; Kocabekir et al 2008; Hayat et al 2009).

Steel is widely used in automotive industry. It is important for its performance features as a material used either for automobile body or structural pieces such as chassis and wheels (Speich 1997). Dual phase (DP) steel is one of the most important advanced high-strength steels (AHSS). This steel has particular characteristics such as its microstructure and superior mechanical properties (Hayat 2010). DP steels provide very valuable economic and technologic benefits such as easy forming, even more strength after process of forming, low and delayed deformation osculation (Erdogan 2002, 2003; Demir and Erdogan 2008).

\footnotetext{
*Author for correspondence (ibrahimsevim33@gmail.com)
}

DP450 and DP600 steel materials used in this study are commercial DP steels. Galvanized DP steel sheets are widely used in automotive industry for their better corrosion resistance property. The effects of galvanizing process on weldability of DP450 and DP600 automotive steels have been investigated. Microstructure, hardness, tensile shear tests and $\mathrm{X}$-ray diffraction (XRD) analysis have been used for assessing weldability of the steels. The effects of welding parameters (welding current and welding time) on indentation depth, nucleus diameter, nugget diameter, nugget height and nucleus size ratio have been investigated.

\section{Experimental}

\subsection{Materials}

In this study, $1.0 \mathrm{~mm}$ thickness DP450 and $1.2 \mathrm{~mm}$ thickness DP600 galvanized (coated) and ungalvanized (uncoated) commercial steels were used. Chemical compositions of these samples are given in table 1 . The coating of weld area $(30 \times 30 \mathrm{~mm})$ was cleaned from galvanization under laboratory conditions by submerging them into $\mathrm{HCl}$ (hydrochloric) acid and is shown schematically in figure 1. Galvanized specimens were coded as ' $G$ ' and ungalvanized ' $U$ '.

\subsection{Welding process}

The spot weld samples were prepared according to DIN 17440 standards and subjected to spot resistance welding in a Baykal SPP60 welding machine as given in figure 2. The capacity of the welding machine was $60 \mathrm{kVA}$. Before joining, 
Table 1. Chemical composition of base metals (wt.\%).

\begin{tabular}{lllllllllll}
\hline Specimens & $\mathrm{C}$ & $\mathrm{Si}$ & $\mathrm{Mn}$ & $\mathrm{Cr}$ & $\mathrm{Ni}$ & $\mathrm{Nb}$ & $\mathrm{Ti}$ & $\mathrm{V}$ & $\mathrm{Mo}$ & $\mathrm{Fe}$ \\
\hline DP600 & 0.11 & 0.182 & 1.6 & 0.34 & 0.027 & 0.0037 & 0.002 & 0.0035 & 0.098 \\
DP450 & 0.054 & 0.129 & 1.32 & 0.51 & 0.02 & 0.0043 & 0.001 & 0.004 & 0.0029 & Balance \\
\hline
\end{tabular}



(a)

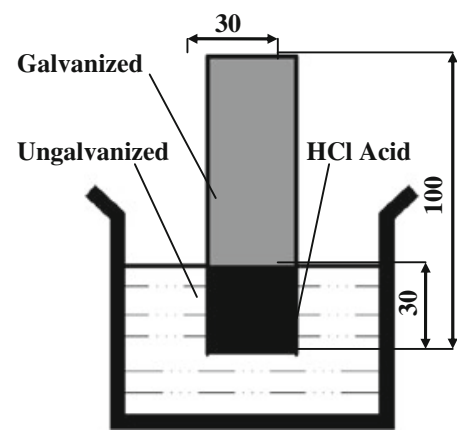

(b)

Figure 1. Dimensions of welded specimens (a) and pre-joining removal of galvanized coating (b).

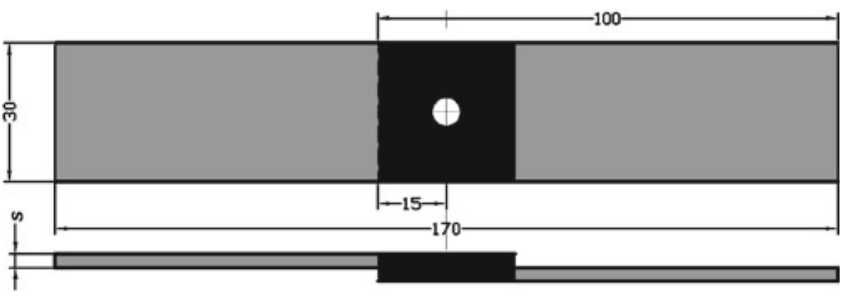

Figure 2. Welded samples according to DN17440.

surfaces of the samples were cleaned by submerging in alcohol and then welded using a conical water-cooled electrode made from a $\mathrm{Cu}-\mathrm{Cr}$ alloy. Diameter of the contact surface of the electrode was $8.0 \mathrm{~mm}$. The specific force of pressing of the electrode was $600 \mathrm{MPa}$. Variables of the study were weld current, time, materials composition and coating condition. Welding processes were carried out by using 3-5-7$9 \mathrm{kA}$ weld current and 10-20-30-40 cycles $(1$ cycle $=0.02 \mathrm{~s})$ weld time.

\subsection{Mechanical tests and metallographic evaluation}

All series of welded joints were exposed to tensile-shear test in order to determine the joint shear strengths as shown in figure 2. In order to determine tensile shear load-bearing capacity of weldment, three test samples were prepared for each of the weld variable. Samples were tested by using Zwick type servo hydraulic universal testing machine. Tensile shear load values were obtained from the load-extension graphs. The Vickers microhardness measurement across the

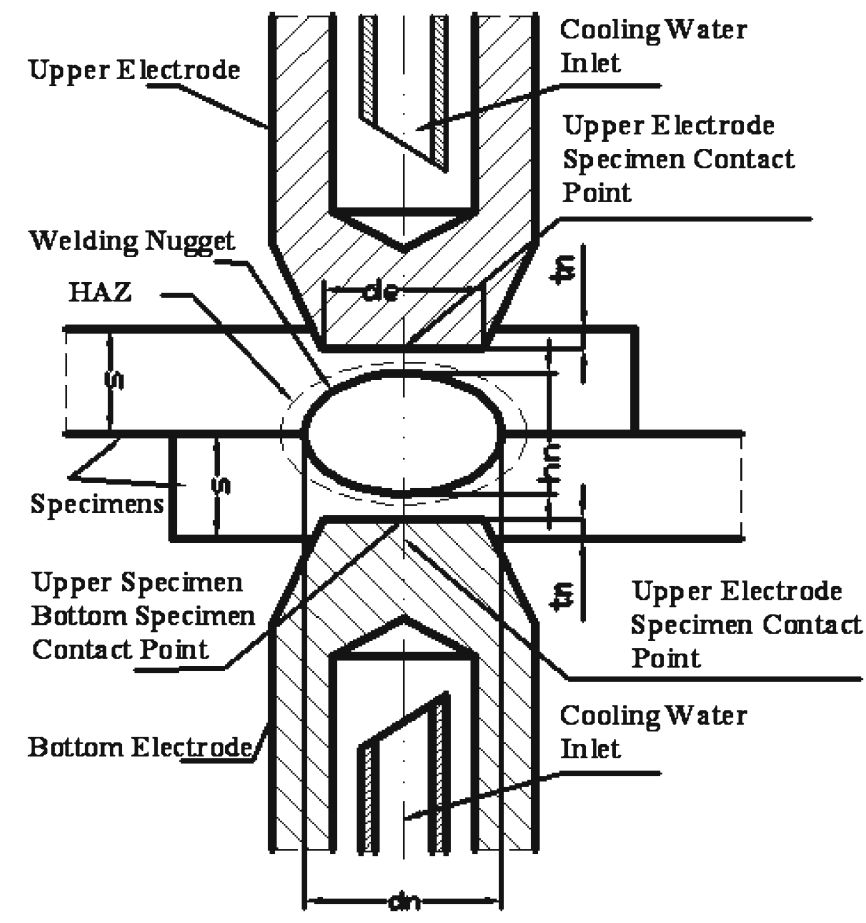

Figure 3. Weld nugget geometry (dn: nucleus diameters, tn: deformation depth, hn: heights of nucleus and de: electrode width).

weld nugget, heat-affected zone (HAZ) and base metal was carried out with a load of $200 \mathrm{~g}$. Transverse sections of the weld passing through the weld nugget as well as a similar section of the base plates were prepared by standard metallographic procedure. Optical examination of specimens was 
carried out using a Nikon DIC microscope. Nucleus diameters $\left(d_{\mathrm{n}}\right)$ and heights of nucleus $\left(h_{\mathrm{n}}\right)$ were measured; and nucleus size ratios $\left(h_{\mathrm{n}} / d_{\mathrm{n}}\right)$ were calculated by means of an optical microscope as seen in figure 3.

\section{Results and discussion}

\subsection{Microstructure}

Microstructure photographs of the specimens welded at different parameters are given in figures 4(a) and (b). It can

(a)



(b)

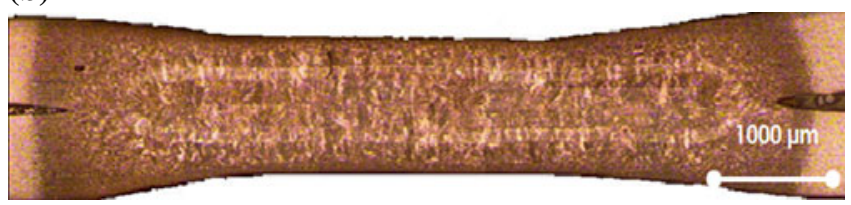

Figure 4. Microstructure photographs of specimens welded at different parameters: (a) DP450U, 3kA-10c and (b) DP450U, $9 \mathrm{kA}-40 \mathrm{c}$. be seen here that weld nucleus diameter is smaller in lower weld time and weld current values in both specimen groups (coated and uncoated). It is also reported in other studies that heat input increases when weld current and time increased as formulated here (Aslanlar 2006).

$$
Q=I^{2} \cdot R \cdot t
$$

where $Q$ is the generated heat $(J), I$ the current (Ampere), $R$ the resistance of the work $(\Omega)$ and $t$ the time of current (s).

The expansion of weld nucleus and HAZ with increase in heat input is an expected result (Gupta et al 1990; Sharma et al 1993; Vural and Akkus 2004; Vural et al 2006; Hayat et al 2007; Zhang et al 2011). Bonding occurred at $9 \mathrm{kA}, 40$ cycles as seen in figure 4(b). Bonding was not observed at $3 \mathrm{kA}, 10$ cycles. Bonding occurred at higher heat input.

\subsection{Nugget diameter and electrode indentation depth}

The effect of coating, weld current and weld time on the nugget diameter of DP450G, DP450U, DP600G and DP600U specimens is given in tables 2 and 3. Different nugget diameters occurred in uncoated DP450 and DP600 specimens. As seen in tables 2 and 3, nugget diameters of DP450 specimens are smaller than DP600 specimens. This result can be explained with thickness of specimens and chemical composition. Heat input in welding zone increases

Table 2. DP450G-DP450U nugget photographs of spot-welded specimens.

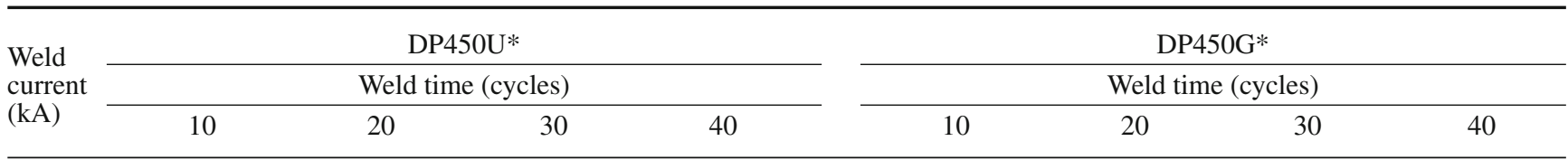

3
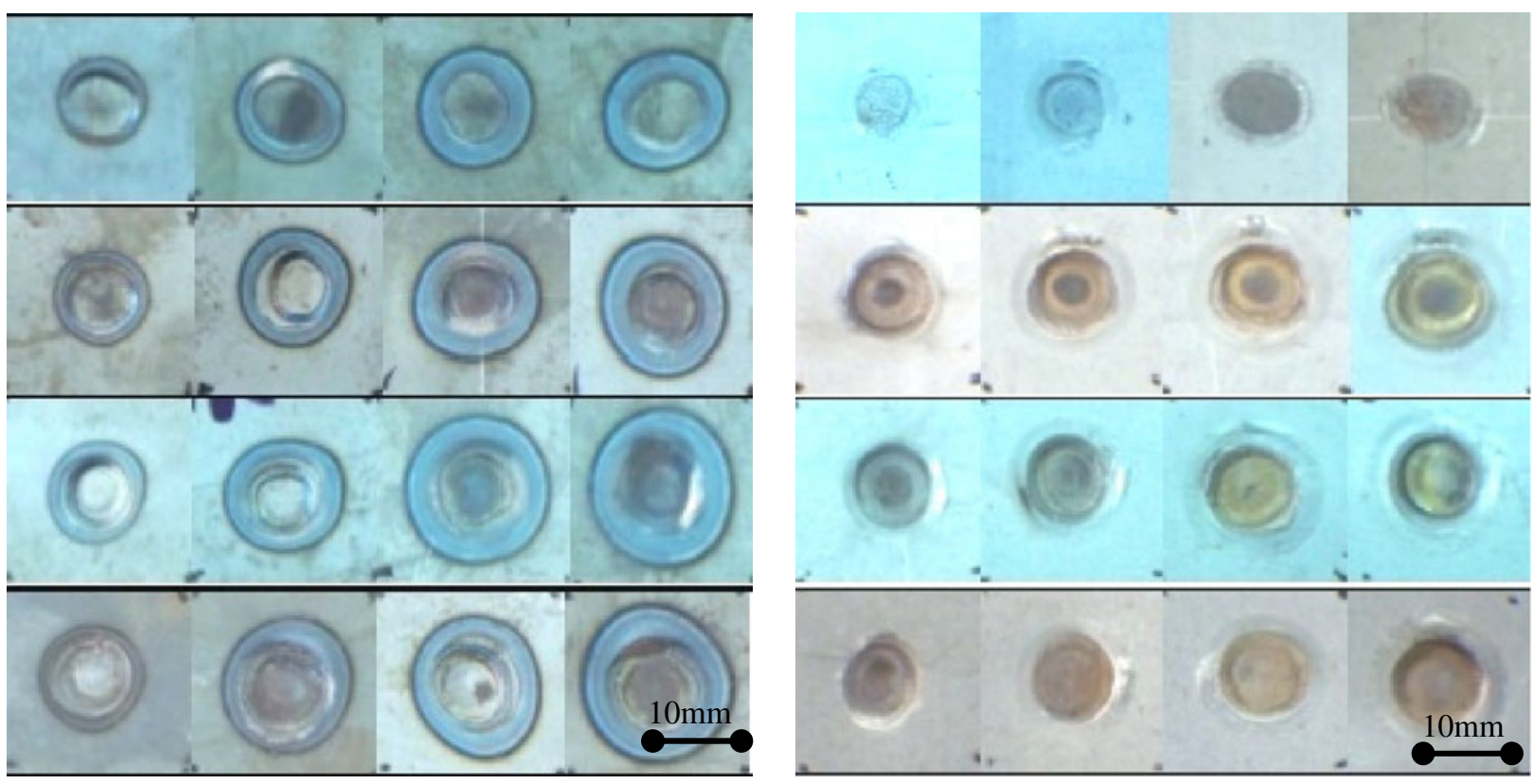

$* \mathrm{U}$, uncoated and $\mathrm{G}$, galvanized. 
as the thickness decreases. For same welding time, bigger nugget diameter was obtained in thinner sheets joint. The Cr content of DP450 steel is 50\% higher than DP600. The amount of $\mathrm{Cr}$ affects heat conductivity. High $\mathrm{Cr}$ content of DP450 decreases heat conductivity and nugget diameter. High resistance value in spot welding is a factor increasing heat input. Wider nugget diameter observed in uncoated specimens were compared to zinc coated ones as seen in tables 2 and 3. This situation can be explained with greater heat generation at the interface of coated samples than uncoated samples. Indentation depth increased with increase in weld current and time as given in figure 5. In tables 2 and 3, it is seen that the indentation depth of uncoated samples is higher than coated samples. This can be explained with plastic deformation. Plastic deformation rate is affected by heat input.

Table 3. DP600G-DP600U nugget photographs of spot-welded specimens.

\begin{tabular}{|c|c|c|c|c|c|c|c|c|}
\hline \multirow{3}{*}{$\begin{array}{l}\text { Weld } \\
\text { current } \\
(\mathrm{kA})\end{array}$} & \multicolumn{4}{|c|}{ DP600U* } & \multicolumn{4}{|c|}{ DP600G* } \\
\hline & \multicolumn{4}{|c|}{ Weld time (cycles) } & \multicolumn{4}{|c|}{ Weld time (cycles) } \\
\hline & 10 & 20 & 30 & 40 & 10 & 20 & 30 & 40 \\
\hline
\end{tabular}

3
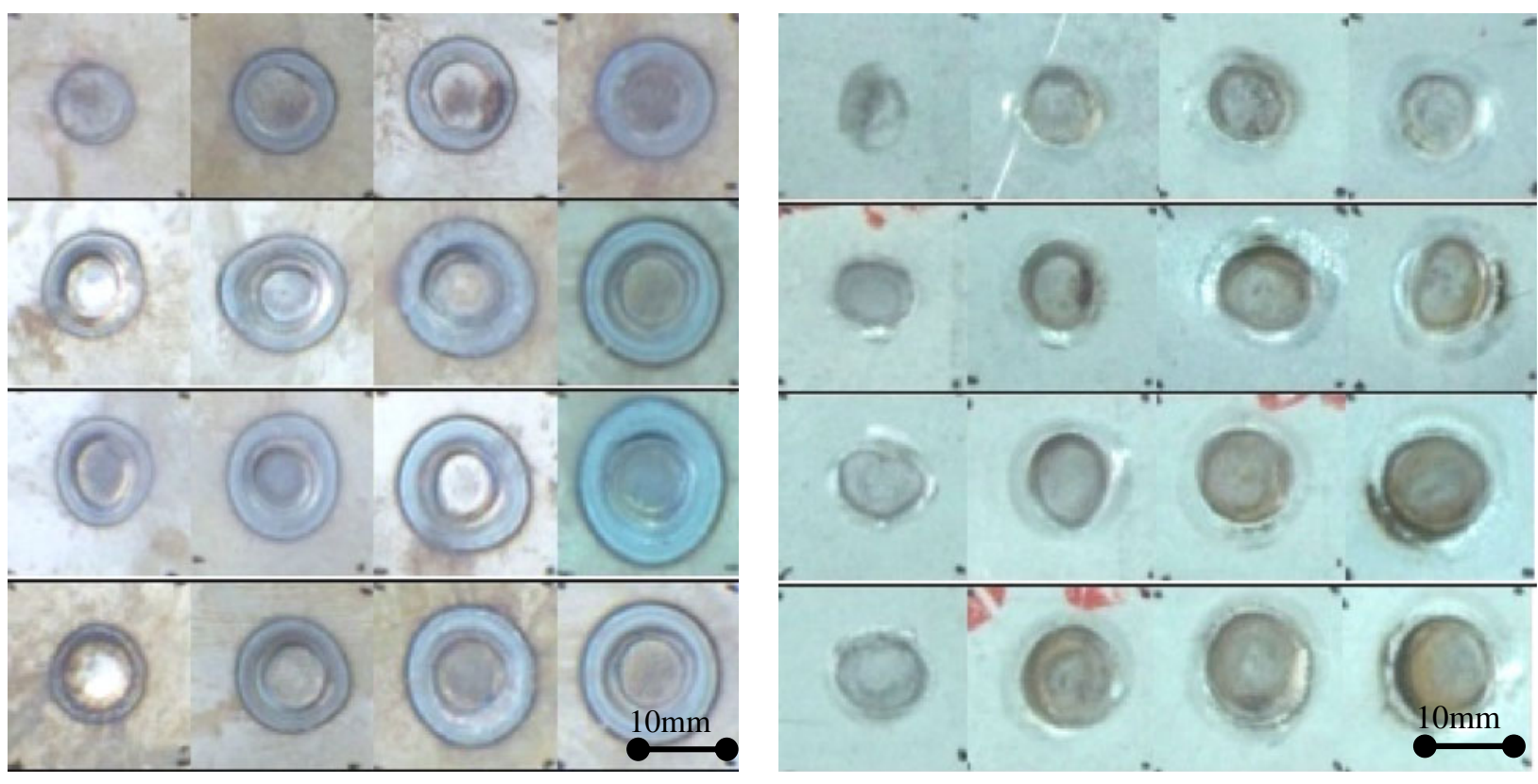

$* \mathrm{U}$, uncoated and $\mathrm{G}$, galvanized.

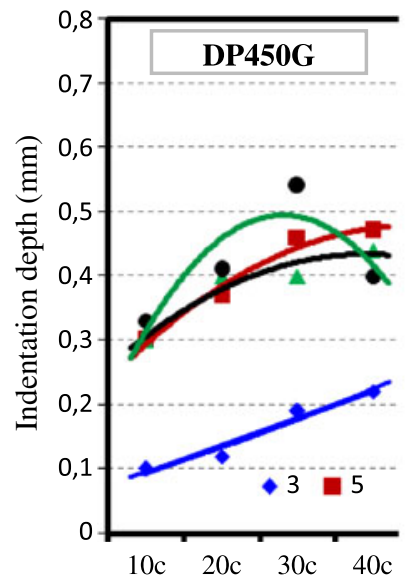

(a)

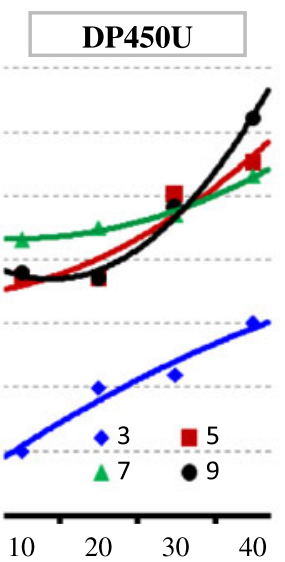

Weld time (cycle)

(b)



(c)



(d)

Figure 5. Effect of weld current and galvanized coating on indentation depth. 


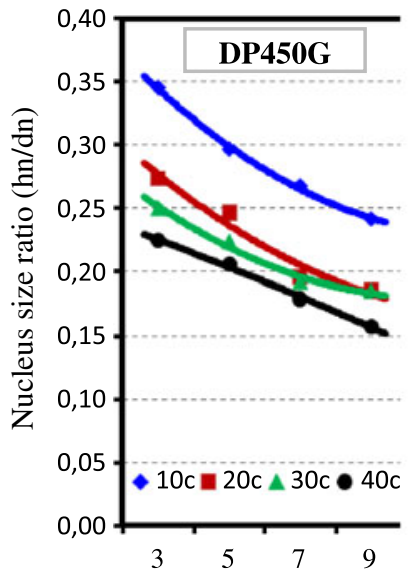

(a)

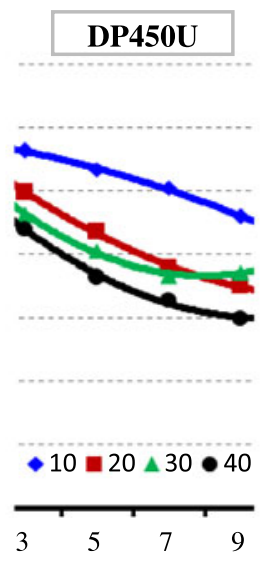

(b)

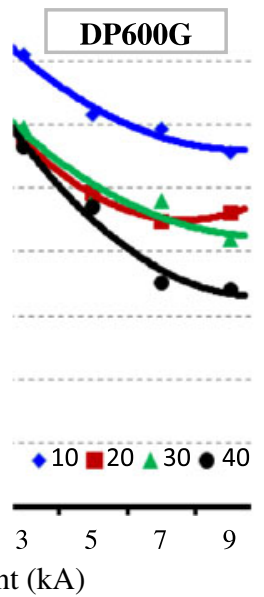

(c)

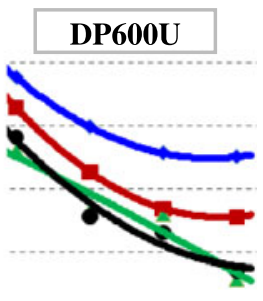

- $10 \backsim 20 \triangle 30 \bullet 40$

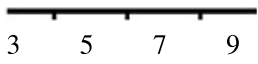

Figure 6. Effect of weld time, current and coating on nucleus size ratio.


Figure 7. Typical microhardness profiles of DP450G, DP450U, DP600G and DP600U steels is after spot welding on different parameters. 



Figure 8. Effect of weld current on tensile shear strength in DP450 and DP600 galvanized and ungalvanized specimens.

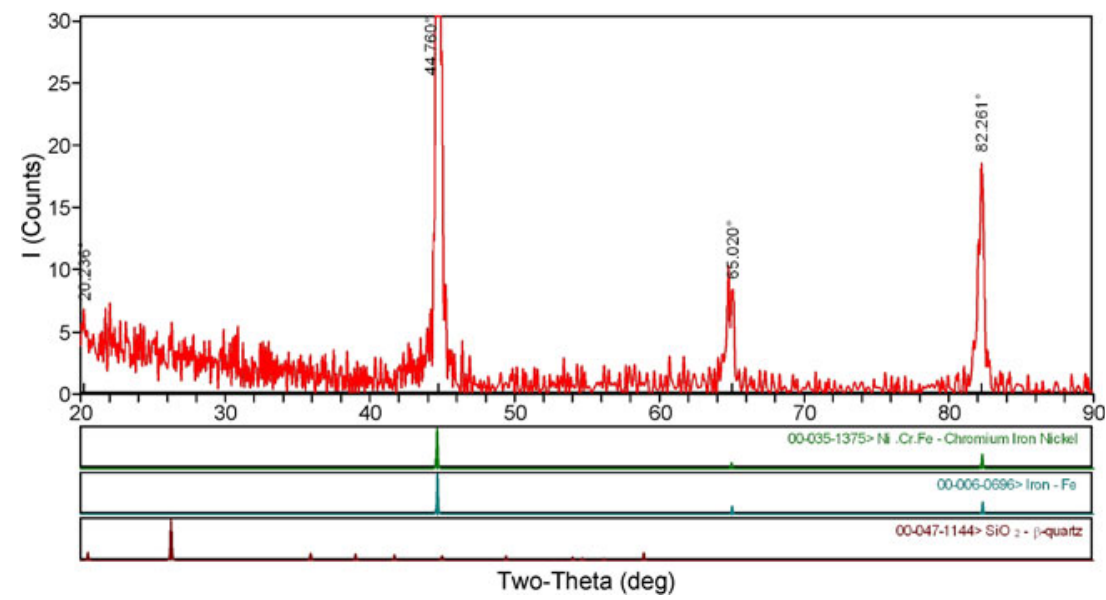

Figure 9. XRD analysis of weld metals of DP450-DP600 (Welding conditions: $7 \mathrm{kA}$, 40 cycles).

The effect of weld time, current and coating on nucleus size ratio is seen in figure 6. Experimental data in figure 6 show that nucleus size ratio reduces when weld current increases. Size ratio affects bonded area at the interface of the weld. Higher size ratio was observed at wider bonded area. 


\subsection{Microhardness}

Figure 7(a-d) shows hardness profiles of spot-welded galvanized and ungalvanized DP450 and DP600 DP steels. Hardness values of both coated and uncoated specimens were similar in all welding conditions. Microhardness values increased up to $\sim 440 \mathrm{HV}$ in weld metal. High values of hardness can be explained with martensitic formations of alloy elements (Mn, Si, Cr, etc.) There was a slight increase in microhardness values in weld metal and HAZ with increase in cycle values as seen in figure 7 . This result may be explained with increasing heat input depending on increase in weld current and time.

\subsection{Tensile load bearing capacity}

The effect of weld current on tensile experiment results in galvanized and ungalvanized specimens as shown in figure $8(a-d)$. The graphics demonstrate an increase in tensile load-bearing capacity (TLBC) with increasing weld current. TLBC was observed at $7 \mathrm{kA}$ value in all specimens. TLBC of DP600 specimen is higher than that of DP450. This difference may be due to the higher strength value of the DP600 specimen. Coating had a negative effect on joining at low weld current and time values in DP450 and DP600 specimens. TLBC increased depending on the increase in weld time. Increasing heat input provides joining at a larger area. Indentation depth of galvanized specimens was lesser than that of ungalvanized specimens at 10 cycles. At lower weld time values, coating prevents steady transmission of electric current and causes heat input to remain at insufficient levels.

\subsection{XRD analysis}

XRD analysis of joint interface of DP450 and DP600 sheets is given in figure 9. $\mathrm{NiCrFe}$ and $\mathrm{SiO}_{2}$ (beta-quartz) phases are present in the joint interface. $\mathrm{NiCrFe}$ phase is one of the stainless steel phases. It is supposed that the metal at the joint interface of DP450-DP600 steels may have stainless steel properties.

\section{Conclusions}

This study concentrated on the geometry and mechanical properties of the resistance spot-welded coated-uncoated DP automotive steels. From the results given above, the following conclusions can be drawn.

(I) When welding time and/or current was increased, both nucleus diameter and depth of electrode indentation were increased.
(II) Lower weld time and weld current reduces nucleus diameter.

(III) Bonding occurs at higher cycles and welding time at HAZ in resistance spot welding.

(IV) Increase in $\mathrm{Cr}$ content of DP steels decreases heat conductivity and nugget diameter.

(V) Galvanized coating results in smaller nugget diameter in spot welding of DP steels.

(VI) Indentation depth of uncoated DP steels is higher than that of coated DP steels.

(VII) Hardness values at HAZ of galvanized and ungalvanized DP steels are similar in all spot-welding conditions.

(VIII) Coating has a negative effect on joining performance at low weld current and time values in DP450 and DP600 specimens.

(IX) $\mathrm{NiCrFe}$ and $\mathrm{SiO}_{2}$ (beta-quartz) phases are present in joint interfaces.

(X) When weld current and time increased, load-bearing capacity of joining was increased.

(XI) Increase in weld current and time resulted in coarser nucleus microstructure which took a columnar state and caused an expansion in HAZ.

\section{Acknowledgement}

The authors thank Mr Özcan on behalf of TOFAS AS in Turkey for the kind material support.

\section{References}

Aslanlar S 2006 Mater. Des. 27125

Demir B and Erdogan M 2008 J. Mater. Process. Technol. 20875

Eisazadeh H, Hamedi M and Halvae A 2010 Mater. Des. 31149

Erdogan M 2002 J. Mater. Sci. 373623

Erdogan M 2003 Scr. Mater. 48501

Gupta P, Ghosh P K, Nath S K and Ray S 1990 Z. Metallkd. 81502

Hayat F 2010 J. Fac. Eng. Arch. Gazi Univ. 25701

Hayat F and Sevim I 2012 Int. J. Adv. Manuf. Technol. 431050

Hayat F, Demir B and Acarer M 2007 Sci. Heat Treat. 49484

Hayat F, Demir B, Aslanlar S and Acarer M 2009 Kov. Mater. 4711

Kearns W H 1980 AWS welding handbook 3, American Welding Society (London: Macmillan Press Ltd.) 7th ed., pp. 1-55

Kocabekir B, Kacar R, Gunduz S and Hayat F 2008 J. Mater. Process. Technol. 195327

Sevim I 2005 Kov. Mater. 43113

Sharma P, Ghosh P K and Nath S K 1993 Z. Metallkd. 84513

Speich G R 1997 ASM handbook (ASM International) 5th ed., p. 424

Vural M and Akkus A 2004 J. Mater. Process. Technol. 1531

Vural M, Akkus A and Eryurek B 2006 J. Mater. Process. Technol. 176127

Zhang P, Xie J, Wang Y X and Chen J Q 2011 Sci. Technol. Weld. Join. 16567 